\title{
A High Throughput Serum Paraoxonase Assay for Discovery of Small Molecule Modulators of PON1 Activity
}

\author{
Tiffany L. Graves and John E. Scott*
}

Department of Pharmaceutical Sciences, Biomanufacturing Research Institute and Technology Enterprise, North Carolina Central University, 1801 Fayetteville Street, Durham, NC 27707, USA

\begin{abstract}
PON1 has been demonstrated to be the serum enzyme responsible for detoxifying organophosphate chemical weapons and plays a protective role against atherosclerosis. In order to identify small molecules that modulate PON1 activity in serum, we developed a high throughput kinetic absorbance assay using mouse serum and the organophosphate paraoxon. The $\mathrm{IC}_{50}$ value obtained for the known PON1 inhibitor, 2-hydroxyquinoline, matched the value reported for purified PON1. A compound library was screened resulting in no confirmed activators, but 12 confirmed inhibitors. Seven of these hits also inhibited purified human PON1. One compound was only two-fold less potent than 2-hydroxyquinoline in the serum assay, but 10 -fold more potent against purified PON1. This compound $\left(\mathrm{IC}_{50}=420 \mathrm{nM}\right)$ may be useful towards a chemical probe for PON1. Therefore, this assay has utility as a high throughput assay for discovery of small molecule modulators of PON1 activity that maintain activity in serum.
\end{abstract}

\section{INTRODUCTION}

Atherosclerosis is the number one cause of mortality in Western societies [1]. Atherosclerosis is a disease affecting the arterial blood vessel where multiple plaques form on the arterial wall that grow in size to eventually reduce blood flow. When arteries that affect the heart are involved, the result is coronary heart disease (CHD). Epidemiological studies have identified multiple risk factors for CHD with one of the strongest being low levels of high-density lipoprotein (HDL) $[2,3]$. HDL is a complex and heterogeneous particle with multiple proteins associated with it [4]. Apolipoprotein A-I (apoA-I) is the major structural protein in HDL and it determines the structure and composition of the particle [5]. HDL appears to afford protection from atherosclerosis through at least two mechanisms, reverse cholesterol transport and inhibiting oxidation of low-density lipoprotein (LDL) [6]. The former property reduces the foam cell formation in plaques formed by cholesterol-loaded macrophages. Oxidized LDL has multiple proatherogenic properties, including induction of cholesterol accumulation in macrophages, and potent pro-inflammatory, immunogenic, apoptotic and cytotoxic activities.

Serum paraoxonase (PON1) is one of three members of the PON family of enzymes that includes PON2 and PON3 [1]. PON1 and PON3 are secreted proteins found in the serum, while PON2 is strictly an intracellular enzyme [1, 7-9]. PON1 and PON3 are expressed primarily in the liver, while PON2 is more widely expressed in a variety of tissues [7, 9]. The three human PON genes share approximately $65 \%$ homology at the amino acid level [10]. PON1 is a calciumdependent glycoprotein consisting of 354 amino acids with a molecular mass of approximately $43 \mathrm{kDa}$. The crystallization

*Address correspondence to this author at the Department of Pharmaceutical Sciences, Biomanufacturing Research Institute and Technology Enterprise, North Carolina Central University, 1801 Fayetteville Street, Durham, NC 27707, USA; E-mail: jscott@ NCCU.EDU of a variant of native PON1 revealed that PON1 has a sixbladed.-propeller structure where each propeller contains four strands [11]. Two calcium ions are present in the protein, one is probably a structural calcium and the other is the catalytic calcium. PON1 was originally identified as the enzyme in serum capable of hydrolyzing the organophosphate paraoxon which is the toxic metabolite of the insecticide parathion [12-14]. In contrast to PON1, PON2 and PON3 lack significant paraoxonase activity $[15,16]$. All three members of the PON family share the ability to hydrolyze aromatic and aliphatic lactones.

PON1 has been demonstrated to have three enzymatic activities - phosphotriesterase, arylesterase, and lactonase [16]. The most frequently used substrate for measuring PON1 phosphotriesterase activity is diethyl p-nitrophenol phosphate, known as paraoxon. This substrate is considered the most specific for measuring PON1 activity in serum since PON1 is the only serum enzyme that hydrolyzes paraoxon [17]. Phenyl acetate is the most frequently used substrate to measure PON1 arylesterase activity because it is one of the best substrates for this enzyme [16]. More recent structure-reactivity studies with PON1 provide strong evidence that its native activity is the lactonase activity [16]. However, the physiological substrates for PON1 are still unknown.

There is a growing body of evidence that implicates a role for PON1 in protection from atherosclerosis. Serum PON1 is almost exclusively found associated with HDL particles and preferentially associates with apoA-I containing HDL particles in vivo and in vitro $[1,18]$. PON1 has subnanomolar affinity $\left(\mathrm{K}_{\mathrm{d}}<10^{-9} \mathrm{M}\right)$ for apoA-I HDL, a significantly higher affinity than for other lipoproteins [18]. In addition, apoA-I HDL stimulates PON1 catalytic activity. ApoA-I HDL stimulated PON1 paraoxonase and arylesterase activity (using phenyl acetate) by approximately 2-fold and 5-fold, respectively, while the lactonase activity of PON1 was stimulated approximately 20 -fold by apoA-I rHDL. This 
data provides evidence that apoA-1 activates the catalytic activity of PON1. PON1 knockout mice (C57BL/6J strain) showed enhanced susceptibility to organophosphate toxicity and atherosclerosis induced by a high fat, high cholesterol diet [17]. HDLs from PON1-deficent mice were unable to prevent LDL oxidation by cells in vitro and HDLs and LDLs from these mice were more susceptible to oxidation than the lipoproteins from wild-type mice. Many other in vitro studies have shown that PON1 inhibits oxidation of lipid in LDL and HDL [9,19]. In addition, transgenic mice overexpressing PON1 show a dose dependent decrease in atherosclerotic lesions with increasing expression of PON1 [20]. PON1 has also been shown to inhibit macrophage cholesterol accumulation by several mechanisms, including attenuation of cellular uptake of oxidized LDL by the scavenger receptor $\mathrm{CD} 36$, inhibition of macrophage cholesterol biosynthesis, and stimulation of macrophage cholesterol efflux [21-23]. The His115-His134 catalytic dyad of PON1 is essential for PON1-mediated inhibition of LDL oxidation and stimulation of macrophage cholesterol efflux, indicating that PON1 enzymatic activity is required for at least these two in vitro anti-atherogenic functions [24]. PON1 has been shown to induce lysophosphatydalcholine (LPC) in macrophages and that LPC generation in macrophages by PON1 is dependent on the His catalytic dyad [24]. LPC was shown to directly stimulate rHDL mediated cholesterol efflux from macrophages. Taken together, these data suggested a model wherein PON1 lactonase activity is responsible for lactonizing oxidized lipids in LDL or cells and then hydrolyzing the resultant lactones to free the carboxylic acid and LPC.

In humans, PON1 activity is inversely related to the risk of cardiovascular diseases [25]. A recent study of the distribution and activity of PON1 in diabetes patients found an abnormal serum PON1 distribution [26]. In a prospective study using men in South Wales, PON1 paraoxonase activity was demonstrated to be a predictive risk factor for CAD independent of other established risk factors [27]. The PON1 activity in individuals varies by 10 - to 40 -fold [25]. Smoking, degraded cooking oil, and trans fats have all been reported to lower PON1 activity [28-30]. In contrast, polyphenols, moderate alcohol consumption and the cholesterol lowering drug simvastatin have all been reported to increase PON1 activity [31-33]. Therefore, one of the antiatherogenic effects of statins may be through indirect transcriptional upregulation of PON1 gene expression. A recent in vitro study demonstrated that aspirin dramatically up-regulated the transcription of PON1 in HepG2 cells and normal rat hepatocytes [34]. Taken together, research on PON1 has led to the hypothesis that therapeutic agents that increase serum PON1 activity may have antiatherogenic activity in humans. In addition, therapies that cause a rapid short term enhancement of PON1 catalytic activity may be advantageous in protection pre- or post-exposure to some organophosphate nerve agents. Thus, a small molecule drug that is able to immediately increase the catalytic activity of PON1 already in the blood may have therapeutic advantages in protection from chemical warfare agents.

Herein we describe the development and proof-ofprinciple testing of a high throughput assay for discovery of small molecule activators and inhibitors of PON1 activity. Serum was used as the source of PON1 where it is closest to its native environment. In addition, any resulting hits will have at least some activity at high serum concentrations. Small molecule activators of PON1 may have use as research tools and/or lead to therapeutic agents, while potent and selective inhibitors of PON1 could be useful as research tools in exploring the biological function of PON1.

\section{MATERIALS AND METHODOLOGY}

\section{Reagents}

All common reagents such as Tris- $\mathrm{HCl}, \mathrm{CaCl}_{2}$, and dimethyl sulfoxide (DMSO) were reagent-grade quality obtained from Thermo Fisher Scientific (Waltham, MA) or Sigma-Aldrich (St. Louis, MO). 2-hydroxyquinoline (2HQ), paraoxon and phenyl acetate were also obtained from SigmaAldrich. Raw untreated mouse serum was purchased from Biomeda Corporation (Foster City, CA) and Genetex, Inc (San Antonio, TX). Purified human PON1 (catalog \# 0801384) was obtained from ZeptoMetrix Corporation (Buffalo, NY). The 384-well plates (catalog \#3702) for the serum assay were from Corning Incorporated (Corning, NY) and for the purified PON1 assay, UV transparent plates (catalog \# 781801) from Greiner Bio-One (Monroe, NC) were used. The compounds for screening and $\mathrm{IC}_{50}$ determinations were obtained from the Asinex Corporation (Moscow, Russia).

\section{Serum Paraoxonase Assay}

The assay was developed with a final volume of $50 \mu \mathrm{l}$ and in 384-well plate format to match the intended screening format. The serum paraoxonase assay was performed by the addition of compound to the well of a 384-well plate followed by the addition of diluted serum and then the reaction was initiated by addition of the paraoxon. Compounds, serum, and paraoxon were diluted with assay buffer consisting of $50 \mathrm{mM}$ Tris $\mathrm{pH} 8.0$ and $1 \mathrm{mM} \mathrm{CaCl}$. In assay development experiments done by hand, typically the volumes for compound (or DMSO), serum and paraoxon were 10, 20, and $20 \mu \mathrm{l}$, respectively, giving a final volume of $50 \mu \mathrm{l}$. The automated assay used different volumes as described below, but with the same final reagent concentrations. The paraoxon was used at the final concentration of $1 \mathrm{mM}$ which is close to its reported $\mathrm{Km}$ value [16] and the commonly used concentration for measuring PON1 activity. Immediately after initiation of the reaction with paraoxon, the plate was read in kinetic mode in a SpectraMax384 (Molecular Devices, Sunnyvale, CA) at a wavelength of $410 \mathrm{~nm}$. After a 5 second plate shake by the instrument, a total of 4 reads for every well were taken with one read performed every 33 seconds. The velocity of the reaction in milli-absorbance units per minute ( $\mathrm{mU} / \mathrm{min})$ was calculated by linear regression by the instrument software. Assay development experimental data points were performed in at least triplicate determination. Error bars for data points represent standard deviations. Z'factor values were derived by the published formula with Z'factors of $0.5-1.0$ indicating that an assay is robust for screening [35].

\section{High Throughput Screen}

For the high throughput screening of the Asinex chemical library, $0.5 \mu \mathrm{l}$ of $1 \mathrm{mM}$ compound in $100 \%$ DMSO was added to dry 384-well plates using a Biomek NX (Beckman Coulter, Inc., Fullerton, CA), resulting in a final compound concentration of $10 \mu \mathrm{M}$ for the primary screen. This dry spotting of compounds into assay plates was performed as a 
routine HTS method of conserving compound stock solutions. This spotting method has been validated for transfer of $0.5 \mu \mathrm{DMSO}$ with a CV of $6.3 \%$ and relative inaccuracy of $2.0 \%$. The Biomek NX automated liquid dispenser was also used to deliver all assay reagents to the wells. To the plates containing compound, $40 \mu \mathrm{l}$ of mouse serum diluted in assay buffer was added to give a final concentration of $15 \%$ serum. Subsequently, $10 \mu \mathrm{l}$ of paraoxon diluted in assay buffer was added with the BioMek NX, followed immediately by a kinetic read of the plate in the plate reader. Final assay concentrations were $15 \%$ serum, $1 \mathrm{mM}$ paraoxon, $10 \mu \mathrm{M}$ compound, $1 \%$ DMSO (from compound), $0.5 \%$ methanol (from paraoxon stock solution) and $1 \mathrm{x}$ assay buffer. Maximum (max) signal positive control wells contained only DMSO (no compound), while the minimum (min) signal control wells were obtained by using EDTA. The definition of a hit was a compound that displayed $50 \%$ inhibition in the primary screen or $75 \%$ activation. $\mathrm{IC}_{50}$ value was defined as the concentration of inhibitor calculated to inhibit $50 \%$ of the assay signal based on a serial dilution of compound. Values were calculated using either a four or three-parameter dose response (variable slope) equation in Graphpad Prism or ActivityBase (IDBS, Alameda, CA). For the $\mathrm{IC}_{50}$ determinations, serial dilutions of compounds were performed in $100 \%$ DMSO with a two-fold or three-fold dilution scheme resulting in 8-10 concentrations of compound starting at a high concentration of $10-80 \mu \mathrm{M}$ compound in the final assay. For the HTS assay, these compound dilutions were spotted onto plates and the assay performed at $1 \%$ DMSO final concentration as described for the primary screen.

\section{Purified PON1 Assay}

The assay using purified PON1 was similar in format to the serum paraxonase assay except for the following changes. PON1 (type AA) purified from human serum was purchased from ZeptoMetrix and used in the assay instead of serum. Phenyl acetate was used at $1 \mathrm{mM}$ and the phenol product detected by absorbance measured at $270 \mathrm{~nm}$ in UV transparent 384-well plates. Since these assays were performed by hand instead of by automation, the assay volumes were changed. All reagent dilutions were done using assay buffer. To the bottom of the well, $10 \mu \mathrm{l}$ of compound dilution was added followed by $20 \mu \mathrm{l}$ of PON1 enzyme diluted in assay buffer. The final concentration of enzyme was 15 $\mathrm{ng} /$ well or $7 \mathrm{nM}$. After addition of enzyme, $20 \mu \mathrm{l}$ of phenyl acetate diluted in assay buffer was added to start the reaction giving a final volume of $50 \mu \mathrm{l}$. The plate was then immediately read in the plate reader (without plate shaking) to generate initial velocity values. Final DMSO concentrations were kept at 0.25 to $0.5 \%$ DMSO.

\section{RESULTS}

\section{Assay Optimization}

The optimal concentration of serum to use in the serum PON1 assay was determined by varying the percentage of serum in the final reaction (Fig. 1). The rate of the reaction increased in a linear fashion up to $15 \%$ serum, after which it became non-linear. The reason for the loss in linearity, i.e. lower than expected velocities at $>15 \%$ serum concentrations, appears to be due to the high absorbance of the serum; studies in which the reactions were stopped and diluted show a linear increase in product up to the highest concentra- tion of serum tested $(60 \%)$ (data not shown). The serum concentration that was chosen was $15 \%$ and this concentration was used in all subsequent experiments. The linearity of the reaction was determined over extended times to provide information on how quickly the reaction needed to be read in the plate reader after initiation of the reaction with substrate (Fig. 2). The reaction rate was linear for at least 20 minutes indicating that there is ample time to read the plate after addition of paraoxon.

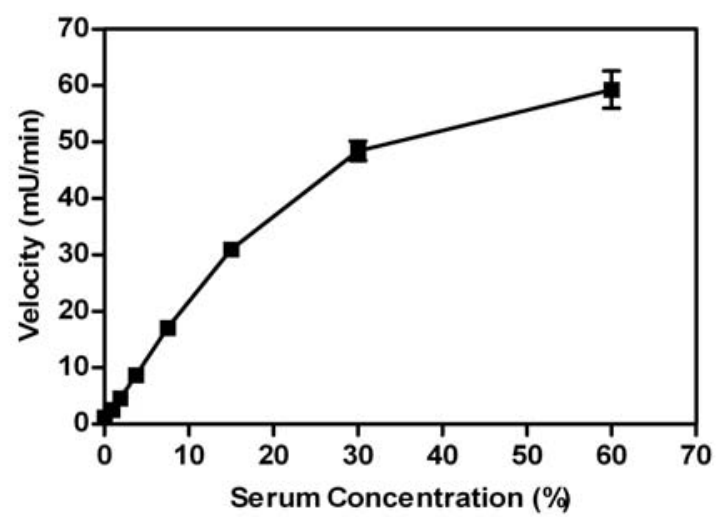

Fig. (1). Reaction velocities at different serum concentrations. Reaction velocities in milli-absorbance units per minute (mU/min) were obtained for the indicated serum concentrations measured as percentage of the final reaction. Data points were performed in triplicate determination and error bars represent standard deviations. Data are representative of two independent experiments.

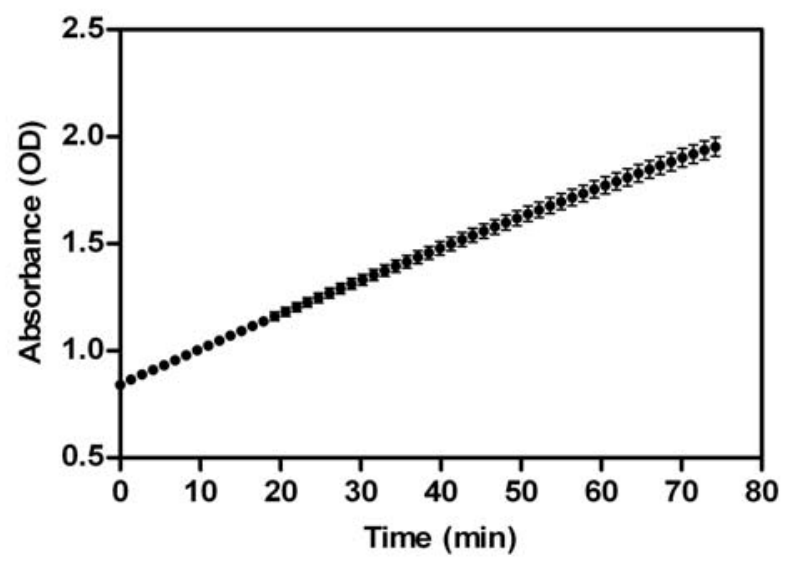

Fig. (2). Reaction time course. Absorbance (optical density) was recorded over time for six replicate reactions initiated at time 0 . Serum concentration was $15 \%$. Error bars represent standard deviations. Data are representative of two independent experiments.

Since the compounds to be screened were dissolved in DMSO, the tolerance of the assay for DMSO was determined (Fig. 3). The assay was very sensitive to DMSO with some inhibition observed at 0.5 and $1 \%$ DMSO. These results are consistent with a report that various organic solvents inhibit recombinant purified PON1 enzymatic activity [16]. We chose to use $1 \%$ DMSO in the testing of compounds. The stability of the diluted serum at $23^{\circ} \mathrm{C}$ (room temperature) was determined over time and the activity in 
the serum was stable for at least 60 minutes (data not shown).

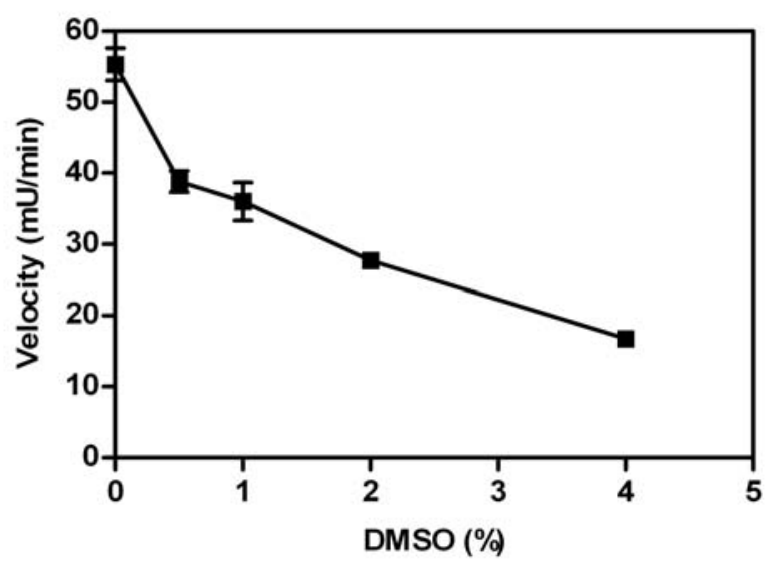

Fig. (3). DMSO Tolerance. Reaction velocities were determined at the indicated concentrations of DMSO, in percentage of the final reaction. Data points were performed in triplicate determination and error bars represent standard deviations.

To validate that the observed catalytic activity was derived from PON1 in the serum, the assay was used to determine the $\mathrm{IC}_{50}$ for the known PON1 inhibitor, 2hydroxyquinoline (2HQ) (Fig. 4).

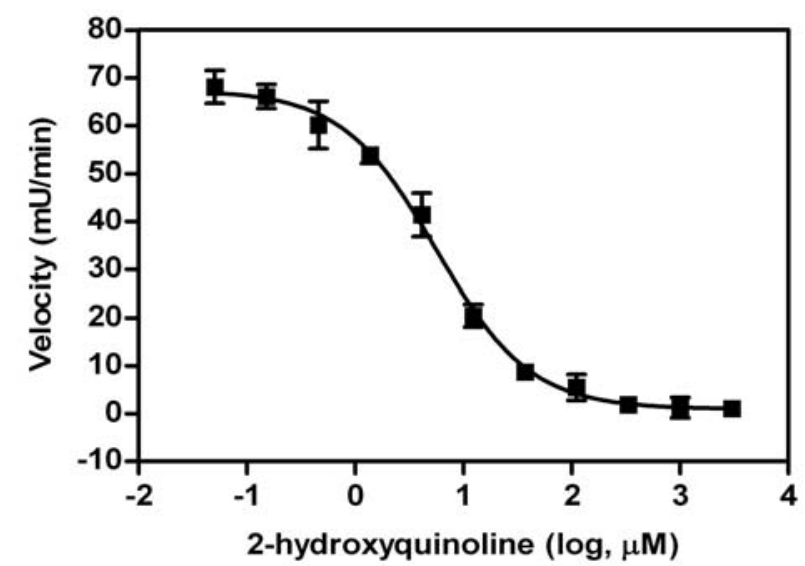

Fig. (4). IC50 value determination for $2 \mathrm{HQ}$ using serum paraoxonase assay. Reaction velocities were measured at the indicated 2HQ concentrations. Final DMSO concentration all 2HQ concentrations was $1 \%$. Data points were performed in triplicate determinations and error bars represent standard deviations. Data are representative of three independent experiments. The average IC50 value of all experiments was $7.9 \mu \mathrm{M}$.

The assay was performed at a constant $1 \%$ DMSO at all concentrations. The average $\mathrm{IC}_{50}$ value obtained was $7.9 \mu \mathrm{M}$ for $2 \mathrm{HQ}$. This $\mathrm{IC}_{50}$ value is in good agreement with the published $\mathrm{K}_{\mathrm{i}}$ value of $3 \mu \mathrm{M}$ for recombinant variant of PON1 [15]. The Cheng-Prusoff equation that relates $\mathrm{IC}_{50}$ to $\mathrm{K}_{\mathrm{i}} \mathrm{sug}$ gests the expected $\mathrm{IC}_{50}$ value to be twice the $\mathrm{K}_{\mathrm{i}}$ value when using a substrate at its $\mathrm{K}_{\mathrm{m}}$ value. This is close to what was observed using this assay where the substrate was used at a concentration that closely matched the reported $\mathrm{K}_{\mathrm{m}}$ value. In addition, the average absolute Hill slope of the $\mathrm{IC}_{50}$ curves was 1.0 which is in agreement with the ideal value of 1.0 expected when measuring inhibition of a single enzyme. Taken together, this data suggests that our PON1 assay is measuring PON1 and only PON1 enzymatic activity.

\section{Assay Variability}

The variability of the assay described above was characterized in a 384-well plate format (Fig. 5). The HTS version of the serum PON1 assay employed work station level automated liquid handling system using the Biomek NX for delivery of compound or DMSO $(0.5 \mu 1)$, diluted serum (40 $\mu 1)$, and paraoxon $(10 \mu 1)$, in that order. The use of the Multidrop (Thermo Fisher) liquid handling instrument was tested for delivery of serum to the plate but automation pattern artifacts were observed possibly due to the viscous nature of the diluted serum. To assess variability of the assay with full automation, all wells of a 384-well plate, except for two columns used as controls, were pre-spotted with $0.5 \mu \mathrm{l}$ of DMSO.

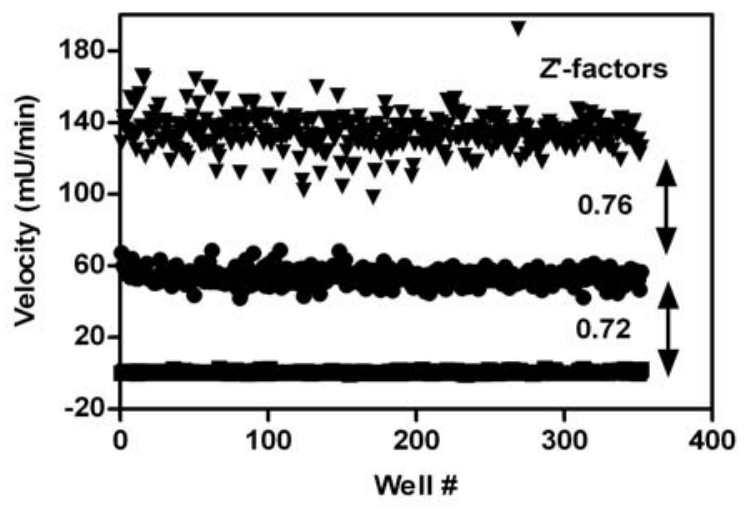

Fig. (5). Serum paraoxonase assay variability assessment. All wells of a 384-well plate, except for two columns used as controls, were pre-spotted with $0.5 \mu 1$ of DMSO. The pre-spotted DMSO plates simulated compound plates to be screened. One plate each was used to determine the maximum signal $(\bullet)$, minimum signal using EDTA ( $\bullet$ ), and a $2 x$ serum concentration $(\boldsymbol{\Delta})$ to mimic $2 \mathrm{x}$ activation of enzymatic activity. The variability for inhibition was determined using the max and min plates while the activation window was determined based on the max and $2 x$ plates. The Z'-factors for the inhibition assay window and the activation assay window are provided. Data are representative of two independent experiments.

The pre-spotted DMSO plates simulated compound plates that were to be screened. The desired screen was one that could detect both activators and inhibitors of PON1 that could function in serum. Therefore, one plate each was used to determine the maximum ( $\max$ ) signal, minimum (min) signal using EDTA to inactivate PON1, and a $2 \mathrm{x}$ serum concentration to mimic $2 \mathrm{x}$ activation of enzymatic activity. This analysis of variability was done twice. The variability for inhibition was determined using the max and min plates while the activation window was determined based on the max and $2 x$ plates. The $\% \mathrm{CV}$ of the max and $2 \mathrm{x}$ plates were all between 6 and $8 \%$, while the $\% \mathrm{CV}$ relative to the assay window for the min plates was 0.8 and $1.4 \%$. The Z'factors for the inhibition assay window were 0.72 for both experiments and for the activation assay window they were 
0.76 and 0.79 . Thus, the assay was highly robust with good variability amenable for high throughput screening for both activators and inhibitors of serum paraoxonase activity.

\section{HTS Results}

A diverse collection of 28,400 small organic molecules purchased from Asinex Corporation were screened for PON1 activation or inhibition (Fig. 6).

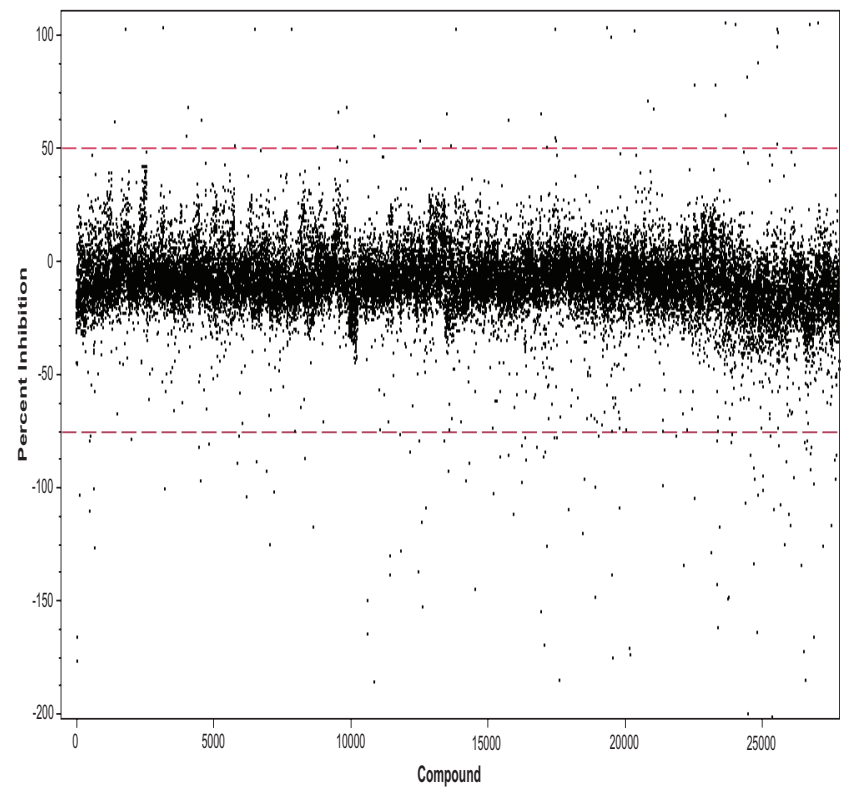

Fig. (6). High throughput screening of a chemical library. The single point screening data is shown in a scattergram showing percent inhibition for each compound tested. The cut-off for inhibition (upper line) and activation (lower line) are shown with dotted lines. Activation values result in negative percent inhibition values. The average $Z$ '-factor using the plate controls was 0.73 .

Each plate had max controls with just DMSO spotted in the wells and min controls where a solution of EDTA/DMSO was used. At the time this assay began screening compounds, software limitations prevented calculations of both inhibition and activation and therefore $2 \mathrm{x}$ activation controls were not performed for the screen. Compound plates were pre-spotted with $0.5 \mu \mathrm{l}$ of $1 \mathrm{mM}$ compound in $100 \%$ DMSO. To these compound plates, $40 \mu 1$ of diluted serum was added followed by $10 \mu \mathrm{l}$ of paraoxon such that the final concentration of compound was $10 \mu \mathrm{M}$ and $1 \%$ DMSO, serum was $15 \%$, and $1 \mathrm{mM}$ paraoxon. Using the plate controls, the calculated average Z'-factor for the whole screen was 0.73 and a day-to-day range of 0.69 to 0.77 . The screen resulted in 36 actives displaying 50\% inhibition and 123 actives with $75 \%$ increased activity (calculates as $-75 \%$ in inhibition formula). Thus, the active rates were $0.13 \%$ and $0.43 \%$ for inhibition and activation, respectively. The use of $75 \%$ activation was chosen to avoid too many compounds for follow-up. The activator actives were triaged by manual inspection of the time course data to reduce false positives due to aberrant points or plotting by the instrument software. After this manual inspection, 51 activator actives $(0.18 \%)$ were re-tested in $\mathrm{IC}_{50}$ format where none of them confirmed activity.

\section{Inhibitors Identified}

In contrast to the activator hits, 12 of the 36 inhibitor hits confirmed activity in $\mathrm{IC}_{50}$ determinations, ranging from 8.5 to $26.6 \mu \mathrm{M}$ (Table 1). The structures of these inhibitors are quite diverse but had some similar scaffold motifs within the group of hits. The most potent one, compound 1, with an $\mathrm{IC}_{50}$ value of $8.5 \mu \mathrm{M}$, was similar in potency to $2 \mathrm{HQ}$, but very different in structure, having a $1,3,4$ thiadiazole scaffold. Compounds 1 and 2 share this scaffold and compound 3 could be considered a related compound with similar "Rgroups", but a isoxazole core instead of the thiadiazole core. There were three hits with an identical 1,4 dihydropyrano[2,3-c] pyrazole core scaffold (compounds 4 - 6) and two hits had a pyrimidine core scaffold (compounds 9 and 10). Four hits were "singlets" without similar scaffolds within the hit series (compounds 7, 8, 11, 12). These compounds had core scaffolds that included a benzo-quinazolinone (compound 7), a quinolinone (compound 8), a thiazepinone (compound 11) and a aza-bicyclo-octane-2-4dione (compound 12). Thus, this serum PON1 assay was successful in finding inhibitors that functioned in the presence of a high concentration of serum.

Potential inhibitors of paraoxonase activity could have multiple potential targets due to the complexity of serum. To test whether these compounds directly inhibited PON1, these hits were tested for inhibitory activity using purified human PON1, instead of serum, in a similar format assay except phenyl acetate was used as the substrate. Phenyl acetate was used instead of paraoxon since phenyl acetate is a better substrate that allowed less enzyme to be used in the reaction, thus conserving PON1 enzyme. The standard inhibitor 2HQ inhibits this purified enzyme assay with an $\mathrm{IC}_{50}$ of $4.4 \mu \mathrm{M}$, similar to the $\mathrm{IC}_{50}$ generated using the serum-based assay (Table 1) and the reported $\mathrm{K}_{\mathrm{i}}$ value of $3 \mu \mathrm{M}$ [15]. The twelve hits from the screen were initially screened at a single compound concentration of $20 \mu \mathrm{M}$ in triplicate to determine which ones inhibit purified human PON1 arylesterase activity (Table 1). Seven of the compounds displayed $>50 \%$ inhibition at $20 \mu \mathrm{M}$ concentration. Thus, $58 \%$ of the screen hits using mouse serum also inhibited purified human PON1. Six of these gave average percent inhibition values similar to or higher than $2 \mathrm{HQ}$. Subsequently, the $\mathrm{IC}_{50}$ values were determined for these six hits using purified PON1 (Table 1). Compounds 4 and 11 gave average $\mathrm{IC}_{50}$ values of 5.3 and 4.8 $\mu \mathrm{M}$, respectively, which is nearly identical to the potency obtained for $2 \mathrm{HQ}$ in the same assay which was $4.4 \mu \mathrm{M}$. Two compounds, compounds 3 and 7, were significantly more potent than 2HQ. Compound 3, with an isooxazole core structure, produced an $\mathrm{IC}_{50}$ of $0.76 \mu \mathrm{M}$ which is 5-fold more potent than 2HQ in the purified PON1 assay. Compound 7, with a benzo-quinazolinone core structure, yielded an $\mathrm{IC}_{50}$ of $420 \mathrm{nM}$. Thus, compound 7 was only two-fold less potent than $2 \mathrm{HQ}$ in the serum assay, but 10 -fold more potent than $2 \mathrm{HQ}$ in the purified PON1 assay. In addition, the average Hill slope value determined from the $\mathrm{IC}_{50}$ determinations was 0.96 , which is very close to the ideal Hill slope value of 1.0. This suggested that the mechanism of inhibition for compound 7 is likely to be via single site binding and not through compound aggregation or non-specific chemical modification of the enzyme. The latter mechanisms usually significantly shift the Hill slope value of $\mathrm{IC}_{50}$ curves [36]. 
Table 1. Activities of Confirmed Inhibitors from Chemical Library Using Serum-Based and Purified PON1 Assays

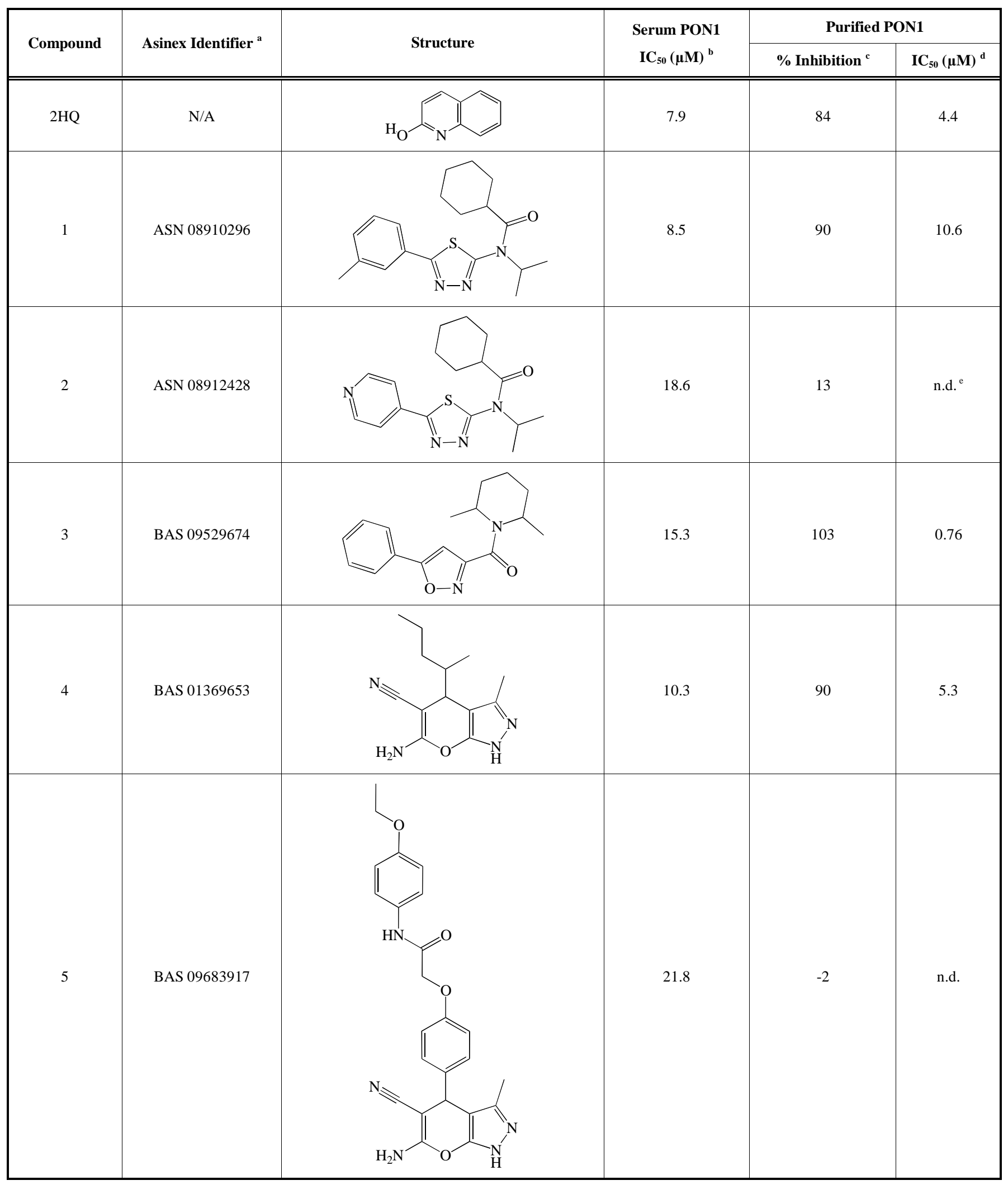


(Table 1). Contd.....

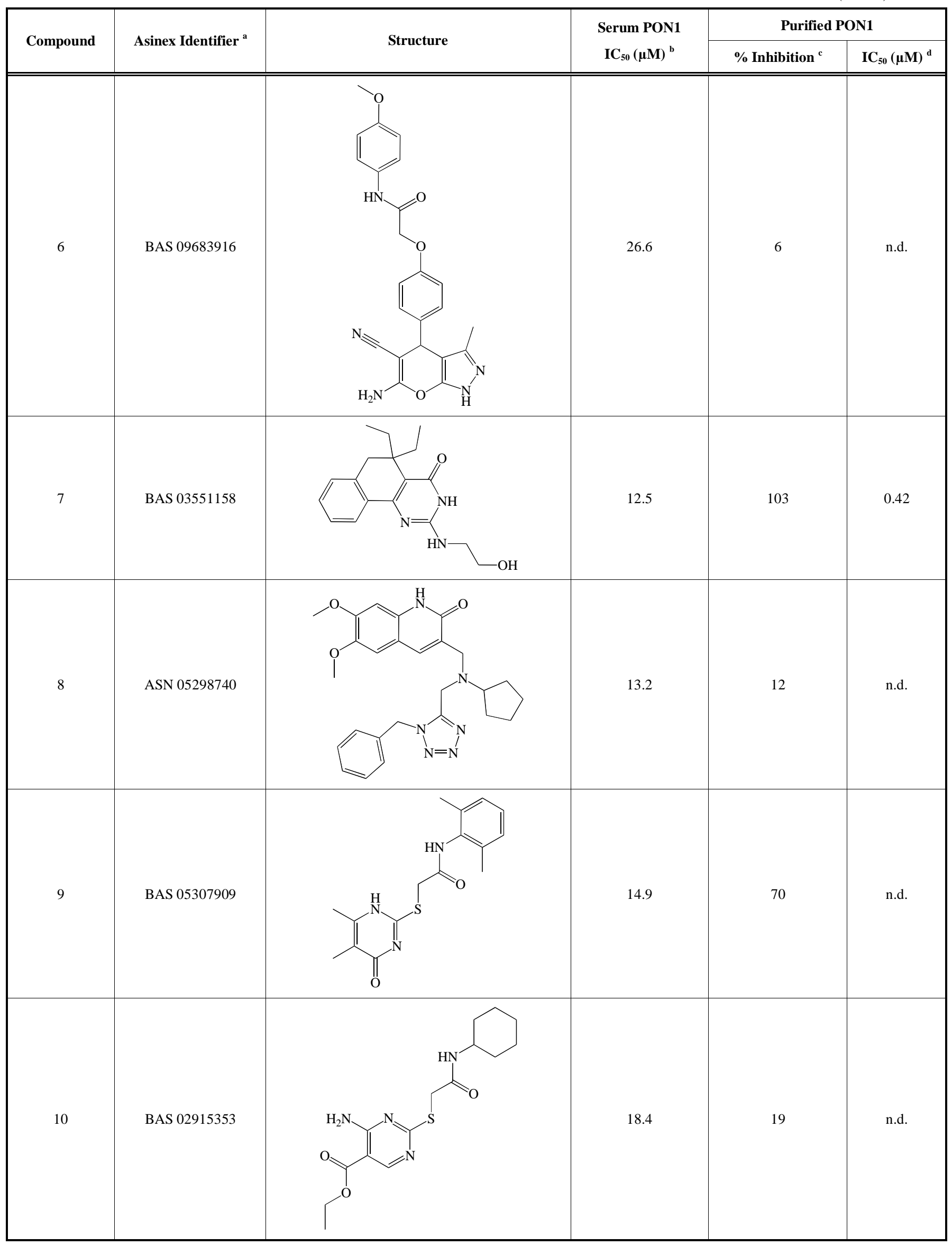


(Table 1). Contd.....

\begin{tabular}{|c|c|c|c|c|c|}
\hline \multirow{2}{*}{ Compound } & \multirow{2}{*}{ Asinex Identifier ${ }^{a}$} & \multirow{2}{*}{ Structure } & \multirow{2}{*}{$\begin{array}{c}\text { Serum PON1 } \\
\mathrm{IC}_{50}(\mu \mathrm{M})^{\mathrm{b}}\end{array}$} & \multicolumn{2}{|c|}{ Purified PON1 } \\
\hline & & & & $\%$ Inhibition $^{c}$ & $\mathrm{IC}_{50}(\mu \mathrm{M})^{\mathrm{d}}$ \\
\hline 11 & BAS 09588626 & & 20.6 & 92 & 4.8 \\
\hline 12 & BAS 01814176 & & 21.1 & 18 & n.d. \\
\hline
\end{tabular}

${ }^{\mathrm{a}}$ Chemical identifier number provided by Asinex Corporation

${ }^{\mathrm{b}} \mathrm{IC} 50$ value determined by the serum paraoxonase assay.

${ }^{\mathrm{c} C}$ Compounds were tested at $20 \mu \mathrm{M}$ in triplicate determinations for each compound. Data are average \% inhibition values from two experiments.

${ }^{\mathrm{d} D a t a}$ are average IC50 values determined from two independent experiments, except for compounds 1 and 6.

${ }^{\mathrm{e}}$ Not determined.

\section{DISCUSSION}

Unlike many serum enzymes, PON1 is anchored in lipoprotein particles - specifically HDL particles. This localization appears to be important for PON1's role in preventing oxidation of HDL and LDL. It has been postulated that PON1 removes oxidized lipid molecules and hence the importance of it residing at the surface of the lipid - its substrates. Thus, PON1 resides in a somewhat unique environment shared by few other serum enzymes. In addition to its atheroprotective role, PON1 also detoxifies some organophosphate toxins. Thus, small molecules that enhance PON1's activity could have potential therapeutic value in slowing atherosclerosis and/or in protection from certain organophosphate-class chemical weapons. In addition, potent inhibitors that have activity in serum could be useful research tools for in vivo and in vitro experiments.

Lipids, interacting proteins and other factors may modify PON1 activity. Examples of this have been reported, including lipids that enhance PON1 activity [37] and phosphate binding protein which appears to stabilize PON1 structure [38]. Therefore, it is conceivable that small molecules activators of PON1 may be discovered that either bind to PON1 directly and activate its activity or modify protein-protein interactions through binding to PON1-associated proteins. In order to potentially discover either type of activator, it was the goal of this work to develop a high throughput assay that could detect activators, as well as inhibitors, of PON1 activity. It was also desirable to maintain PON1 in its native environment and conformation associated with the lipid surface of HDL particles. Therefore, mouse serum was chosen as a source of native PON1. The use of paraoxon as the substrate for PON1 allowed the specific detection of PON1 activity even in the presence of many serum enzymes.

An assay was developed to screen chemical libraries for small molecule activators and inhibitors of paraoxonase activity in serum. PON1 has been shown to be the only enzyme in mouse serum that can hydrolyze paraoxon. Therefore, the source of PON1 used for this PON1 assay was pooled untreated mouse serum and the substrate was paraoxon. Phenotypic cell-based screens are used for screening and characterizing the biological activity of compounds. In analogy to these cell based assays, we have developed a serum-based, rather than cell-based, enzyme assay. Use of serum instead of purified PON1 for a screen has several potential advantages. First, PON1 is closer to its native environment, and potentially its structural conformation, in serum relative to purified enzyme. Native PON1 in serum is bound to the lipid of HDL particles in close proximity with other proteins such as apoA-I and phosphate binding protein which has been shown to associate with PON1 and stabilize it $[38,39]$. Secondly, with the use of whole serum there is the chance of discovering compounds that modify protein-protein interactions that directly or indirectly affect PON1 activity or stability. Thirdly, hits obtained from such a screen will be more likely to function in the high protein environment of serum. Lastly, the high protein content in the assay would be expected to make the assay highly resistant to 'nuisance' hit compounds that inhibit purified enzyme assays through aggregation or covalent modification of the enzyme.

In this report, a kinetic absorbance assay was developed to measure PON1 activity. This is an assay that has traditionally been used to measure PON1 activity, but a high throughput version of the assay using serum as source of enzyme has not been reported previously. The kinetic nature of this assay, as opposed to end point assays, has several advantages. The primary advantage is that colored or otherwise interfering compounds should not be detected as false positives since the assay measures the rate of increase in optical density so colored compounds that absorb will start out at a higher optical density, but have an unchanged rate of increase if they are inactive. However, theoretically there is potential to measure the dissolution of absorbing compounds as they dissolve into water from $100 \%$ DMSO such that they 
falsely appear to increase the reaction rate. Additionally, the linear progress of the reaction can always be verified by examining the raw data which provides assurance of measuring initial rates even if the assay protocol is changed. Hits can be triaged by examination of the linear progression of the reaction to see the quality of the fit, i.e. $\mathrm{R}^{2}$ of the linear fit done by the instrument software. Non-linear progressions were suspect.

The choice of $15 \%$ serum concentration was based on the serum concentration that generated a robust reaction rate (slope) while avoiding turbid higher concentrations that may have interfered with the assay. In time course experiments, this assay remained linear with time for at least 10 minutes which allowed plenty of time between the start of the assay and reading the plate. The DMSO tolerance data indicated the activity is very sensitive to DMSO, with even 0.5 and $1 \%$ DMSO inhibiting PON1 activity. This is consistent with the reported sensitivity of PON1 to organic solvents [16]. To verify activity was from PON1 in the serum, the $\mathrm{IC}_{50}$ value was determined with the assay using $2 \mathrm{HQ}$ and the values obtained matched the reported $\mathrm{K}_{\mathrm{i}}$. In addition, the Hill slope of the $2 \mathrm{HQ} \mathrm{IC}_{50}$ data indicated the inhibition of a single enzyme.

Whole 384-well plate variability studies using prespotted DMSO plates and automation were done to assess the variability in detection of both inhibitors and activators. The results generated $Z$ '-factors of $>0.7$ for both activators and inhibitors, indicating a robust assay for detection of both types of hits.

Screening of the commercially supplied compound set resulted in 123 activators initially identified in the single point screen. A significant number of these (59\%) were easily eliminated by examination of the raw data which showed abnormal reaction progressions (curving of the reaction progression or an abnormal point that resulted in inaccurate linear regression). This type of false positive may result from the measurement of light absorbing compounds dissolving into solution from its original $100 \%$ DMSO solvent. The remaining activator actives, represented $0.18 \%$ of the total compounds screened, did not repeat activity in $\mathrm{IC}_{50}$ assays. Subsequent to the completion of the screen, it was discovered that changing a couple of procedures could potentially decrease the false positive rate for activators. Typically, when the plate was put into the plate reader for kinetic reads, the program was set up to shake the plate for 5 seconds prior to taking the first data point. It was discovered that not shaking the plate before the reads began actually decreased variability. Furthermore, better data was obtained by waiting a approximately 2-3 minutes to read the plate after the initiation of the reaction. This time lag may allow the reaction components (compound, serum and paraoxon) to mix thoroughly and reach a steady reaction rate and allow time for dissolution of light absorbing compounds.

One possible reason that none of the 51 activators could be confirmed may be that these actives were poorly soluble light absorbing compounds and the apparent increase in velocity was actually a result of the compounds slowly dissolving into solution. The lack of repeatable "activity" in $\mathrm{IC}_{50}$ assays may have been due to a somewhat longer time lag between the start of the reaction and plate reading. This longer time lag may have allowed the compounds to become fully dissolved in solution, i.e. reach equilibrium, before the first read time and hence not contribute to the increase in absorbance with time. Another possible explanation for the lack of confirmation of activators may simply be due to variability in the activation aspect of the assay, leading to false positives. Since $2 x$ activation controls could not be performed at the time of screening due to software limitations, the activation variability could not be assessed for the screen. However, the assay development data using $2 \mathrm{x}$ the concentration of serum in variability studies suggested that the assay had reasonable variability in detecting activators.

Seven of the 12 inhibitors (58\%) had some activity against human purified PON1. All three of the most potent inhibitors discovered in the screen also inhibited purified PON1. This data further validated that the screening assay was measuring PON1 activity in the serum. The discovery of inhibitors to purified PON1 demonstrated the utility of the assay to discover inhibitors of PON1 that would maintain at least some inhibitory activity in the presence of serum. There are several possible reasons for the lack of activity against purified PON1 for some of the hits. One possibility is that the purified PON1 is of human origin unlike the mouse PON1 in the serum screen. Though the two species have high homology $(85 \%)$, they are not identical and compound binding sites may have variation. To fully characterize the species specificity and activity of the hits, they should be tested for activity in assays using purified mouse PON1 and human serum. One other possibility is that some compounds may lack aqueous solubility in the absence of facilitating serum protein. In fact, precipitating material in compound dilutions were observed in experiments with compounds 5 and 6, which could explain their lack of activity in the purified PON1 assay. Another possibility for variation in results between the two PON1 assays is that different substrates were used and different residues are required for catalysis of these substrates. However, splitting inhibition of these activities by a small molecule seems unlikely since only one active site has been identified for PON1 and 2HQ inhibits both activities approximately equally (see Table 1). A final possibility is that the inhibitor acts on a PON1 associated molecule that is present in serum and influential to PON1 activity, yet absent in the purified version of PON1.

Interestingly, many new scaffolds unrelated or only distantly related to $2 \mathrm{HQ}$ were discovered to inhibit PON1. It should be noted that several of the structures contain lactam motifs (compounds $7,8,9,11,12$ ) and simple lactams have been reported to weakly inhibit PON1 [40]. The difference in the activity observed in the serum assay and the purified PON1 assay for active compounds varied from nearly the same (compound 1) to a 30-fold shift (compound 7). This is most likely due to compound binding to serum protein and thus shifting the $\mathrm{IC}_{50}$ in the presence of serum. Compound 7 had $\mathrm{IC}_{50}$ values in the serum assay and the purified PON1 assay of 12.5 and $0.42 \mu \mathrm{M}$, respectively. This 10 -fold increase in potency over $2 \mathrm{HQ}$ is noteworthy and suggests that this compound may be a useful research tool. Compounds 1 and 4 are attractive inhibitors because they show less than a two-fold shift in potency in the presence of serum and could be starting points for the discovery of more potent inhibitors of PON1 for research use. An advantage to the compounds described in this report is that they are all commercially available for further study. 


\section{CONCLUSIONS}

We have developed a high throughput kinetic absorbance assay for discovery of small molecule modulators of PON1 activity. The use of mouse serum as the source of PON1 helped ensure that hits in this assay maintain activity in the presence of serum and allowed PON1 to be screened closer to its native environment. The enzyme specificity of this assay was confirmed with the known PON1 inhibitor 2HQ. Variability studies confirmed the robustness of this assay for high throughput screening. A chemical library was screened resulting in no confirmed activators, but 12 confirmed inhibitors. The most potent inhibitors had potencies within two-fold of $2 \mathrm{HQ}$, but were structurally unrelated. These inhibitors were tested to determine if they could inhibit the activity of purified human PON1. Seven of the twelve hits from the screen inhibited purified human PON1. One compound was only two-fold less potent than $2 \mathrm{HQ}$ in the serum assay, but 10 -fold more potent than 2HQ using purified PON1. With an $\mathrm{IC}_{50}$ of $420 \mathrm{nM}$, this compound may be useful in the development of a chemical probe for PON1.

\section{ACKNOWLEDGEMENTS}

The authors would like to thank Mark A. Hughes, Ginger Smith and Jonathan Z. Sexton for their assistance in performing the high throughput screen and database mining. This work was supported in part by a grant from the Golden LEAF Foundation and funds from the State of North Carolina.

\section{REFERENCES}

[1] Ng CJ, Shih DM, Hama SY, Villa N, Navab M, Reddy ST. The paraoxonase gene family and atherosclerosis. Free Radic Biol Med 2005; 38: 153-63

[2] Castelli WP, Garrison RJ, Wilson PW, Abbott RD, Kalousdian S, Kannel WB. Incidence of coronary heart disease and lipoprotein cholesterol levels. The Framingham Study. JAMA 1986; 256 : 2835-8.

[3] Castelli WP. Lipids, risk factors and ischaemic heart disease. Atherosclerosis 1996; 124(Suppl): S1-S9.

[4] Yokoyama S. Assembly of high-density lipoprotein. Arterioscler Thromb Vasc Biol 2006; 26: 20-7.

[5] Pownall HJ, Ehnholm C. The unique role of apolipoprotein A-I in HDL remodeling and metabolism. Curr Opin Lipid 2006; 17: 20913.

[6] Assmann G, Nofer JR. Atheroprotective effects of high-density lipoproteins. Annu Rev Med 2003; 54: 321-41.

[7] $\mathrm{Ng}$ CJ, Wadleigh DJ, Gangopadhyay A, et al. Paraoxonase-2 is a ubiquitously expressed protein with antioxidant properties and is capable of preventing cell-mediated oxidative modification of low density lipoprotein. J Biol Chem 2001; 276: 44444-9.

[8] Draganov DI, Stetson PL, Watson CE, Billecke SS, La Du BN. Rabbit serum paraoxonase 3 (PON3) is a high density lipoproteinassociated lactonase and protects low density lipoprotein against oxidation. J Biol Chem 2000; 275: 33435-42.

[9] Reddy ST, Wadleigh DJ, Grijalva V, et al. Human paraoxonase-3 is an HDL-associated enzyme with biological activity similar to paraoxonase-1 protein but is not regulated by oxidized lipids. Arterioscler Thromb Vasc Biol 2001; 21: 542-7.

[10] Primo-Parmo SL, Sorenson RC, Teiber J, LaBu BN. The human serum paraoxonase/arylesterase gene (PON1) is one member of a multigene family. Genomics 1996; 33: 498-507.

[11] Harel M, Aharoni A, Gaidukov L, et al. Structure and evolution of the serum paraoxonase family of detoxifying and anti-atherosclerotic enzymes. Nat Struct Mol Biol 2004; 11: 412-9.

[12] Aldridge WN. Serum esterases II. An enzyme hydrolyzing diethyl p-nitrophenyl phosphate (E600) and its identity with the A-esterase of mammalian sera. Biochem J 1953; 53: 117-24.
Aldridge WN. Serum esterases. I. Two types of esterases (A and B) hydrolyzing p-nitrophenyl acetate, propionate and butyrate, and a method for their determination. Biochem J 1953; 53: 110-7.

[14] van Himbergen TM, van Tits LJH, Roest M, Stalenhoef AFH. The story of PONI: how an organophosphate-hydrolyzing enzyme is becoming a player in cardiovascular medicine. Netherlands J Med 2006 ; 64: 34-8.

[15] Aharoni A, Gaidukov L, Yagur S, Toker L, Silman I, Tawfik DS. Directed evolution of mammalian paraoxonases PON1 and PON3 for bacterial expression and catalytic specialization. Proc Natl Acad Sci USA 2004; 101: 482-7.

[16] Khersonsky O, Tawfik DS. Structure-reactivity studies of serum paraoxonase PON1 suggest that its native activity is lactonase. Biochemistry 2005; 44: 6371-82.

[17] Shih DM, Gu L, Xia Y, et al. Mice lacking serum paraoxonase are susceptible to organophosphate toxicity and atherosclerosis. Nature 1998; 394: 284-7.

[18] Gaidukov L, Tawfik DS. High affinity, stability, and lactonase activity of serum paraoxonase PON1 anchored on HDL with apoAI. Biochemistry 2005; 44: 11843-54.

[19] Mackness MI, Arrol S, Abbott C, Durrington PN. Protection of low-density lipoprotein against oxidative modification by highdensity lipoprotein associated paraoxonase. Atherosclerosis 1993; 104: 129-35.

[20] Tward,A, Xia YR, Wang XP, et al. Decreased atherosclerotic lesion formation in human serum paraoxonase transgenic mice. Circulation 2002; 6: 484-90.

[21] Fuhrman B, Volkova N, Aviram M. Oxidative stress increases the expression of the CD36 scavenger receptor and the cellular uptake of oxidized low-density lipoprotein in macrophages from atherosclerotic mice: protective role of antioxidants and of paraoxonase. Atherosclerosis 2002; 61: 307-16.

[22] Rozenberg O, Shih DM, Aviram M. Paraoxonase 1 (PON1) attenuates macrophage oxidative status: studies in PON1 transfected cells and in PON1 transgenic mice. Arterioscler Thromb Vasc Biol 2003; 23: 461-7.

[23] Rosenblat M, Vaya J, Shih DM, Aviram M. Paraoxonase 1 (PON1) enhances HDL-mediated macrophage cholesterol efflux via the ABCA1 transporter in association with increased HDL binding to the cells: a possible role for lysophosphatidylcholine. Atherosclerosis 2005; 179: 69-77.

[24] Rosenblat M, Gaidukov L, Khersonsky O, et al. The catalytic histidine dyad of high density lipoprotein-associated serum paraoxonase-1 (PON1) is essential for PON1-mediated inhibition of low density lipoprotein oxidation and stimulation of macrophage cholesterol efflux. J Biol Chem 2006; 281: 7657-65.

[25] Durrington PN, Mackness B, Mackness MI. Paraoxonase and atherosclerosis. Arterioscler Thromb Vasc Biol 2001; 21: 473-80.

[26] Rosenblat M, Kerry R, Aviram M. Paraoxonase 1 (PON1) is a more potent antioxidant and stimulant of macrophage cholesterol efflux, when present in HDL than in lipoprotein-deficient serum: relevance to diabetes. Atherosclerosis 2006; 187: 74-81.

[27] Mackness B, Durrington P, McElduff P, et al. Low paraoxonase activity predicts coronary events in the Caerphilly Prospective Study. Circulation 2003; 107: 2775-9.

[28] James RW, Leviev K, Righetti A. Smoking is associated with reduced serum paraoxonase activity and concentration in patients with coronary artery disease. Circulation 2000; 101: 2252-7.

[29] Kudchodkar BJ, Lacko AG, Dory L, Fungwe TV. Dietary fat madulates serum paraoxonase I activity in rats. J Nutr 2000; 130: 2427-33.

[30] Sutherland WHF, Walker RJ, de Song SA, van Rij AM, Phillips V. Reduced postprandial serum paraoxonase activity after a meal rich in used cooking fat. Arterioscler Thromb Vasc Biol 1999; 19: 1340-7.

[31] Aviram M, Dornfold L, Rosenblat M, et al. Pomegranate juice consumption reduces oxidative stress, atherogenic modifications of LDL, and platelet aggregation: studies in humans and in atherosclerotic apolipoprotein E deficient mice. Am J Clin Nutr 2000; 71: $1062-76$.

[32] van der Gaag MS, van Tol A, Scheek LM, et al. Daily moderate alcohol consumption increases serum paraoxonase activity: a diet controlled, randomized intervention study in middle-aged men. Atherosclerosis 1999; 147: 405-10.

[33] Tomas M, Senti M, Garcia-Faria F, et al. Effect of simvastatin therapy on paraoxonase activity and related lipoproteins in familial 
hypercholesterolemic patients. Arterioscler Thromb Vasc Biol 2000; 20: 2113-9.

[34] Jaichander P, Selvarajan K, Garelnabi M, Parthasarathy S. Induction of paraoxonase 1 and apolipoprotein $\mathrm{A} 1$ gene expression by aspirin. J Lipid Res 2008; 49(10): 2142-8.

[35] Zhang J, Thomas D, Chung Y, Oldenburg KR. A simple statistical parameter for use in evaluation and validation of high throughput screening assays. J Biomol Screen 1999; 4: 67-74.

[36] Feng BY, Simeonov A, Jadhav A, et al. A high-throughput screen for aggregation-based inhibition in a large compound library. J Med Chem 2007; 50: 2385-90.

[37] Nguyen SD, Sok DE. Preferable stimulation of PON1 arylester'ase activity by phosphatidylcholines with unsaturated acyl chains or oxidized acyl chains at sn-2 position. Biochim Biophys Acta 2006; 1758: 499-508.

[38] Rochu D, Renault F, Cléry-Barraud C, Chabrière E, Masson P Stability of highly purified human paraoxonase (PON1): association with human phosphate binding protein (HPBP) is essential for preserving its active conformation(s). Biochim Biophys Acta 2007; 774: 874-83.

[39] Morales R, Berna A, Carpentier P, et al. Serendipitous discovery and $\mathrm{X}$-ray structure of a human phosphate binding apolipoprotein. Structure 2006; 14: 601-9.

[40] Billecke S, Draganov D, Counsell R, et al. Human serum paraoxonase (pon1) Isozymes $\mathrm{Q}$ and $\mathrm{R}$ hydrolyze lactones and cyclic carbonate esters. Drug Metab Dispos 2000; 28: 1335-42

(C) Graves and Scott; Licensee Bentham Open.

This is an open access article licensed under the terms of the Creative Commons Attribution Non-Commercial License (http://creativecommons.org/licenses/by-nc/3.0/) which permits unrestricted, non-commercial use, distribution and reproduction in any medium, provided the work is properly cited. 